\title{
Prevalence of Organic Colonic Lesions by Colonoscopy in Patients Fulfilling ROME IV Criteria of Irritable Bowel Syndrome
}

\author{
Mukesh Sharma Paudel, ${ }^{1}$ Amrendra Kumar Mandal, ${ }^{1}$ Barun Shrestha, ${ }^{1}$ Nandu Silwal Poudyal, ${ }^{1}$ Sudhamshu KC, ${ }^{2}$ Sitaram \\ Chaudhary, ${ }^{1}$ Ramila Shrestha, ${ }^{1}$ Khushboo Goel $^{3}$ \\ 'Gastroenterology Unit, Department of Medicine, Bir Hospital, Nepal, ${ }^{2}$ Hepatology Unit, Department of Medicine, Bir \\ Hospital, Kathmandu, Nepal, ${ }^{3}$ Department of Periodontology and Oral Implantology, B.P. Koirala Institute of Health Sciences, \\ Dharan, Nepal.
}

\section{ABSTRACT}

Introduction: Irritable bowel syndrome occurs as recurrent abdominal pain that is related to defecation and associated with change in frequency and/or form of stool. Few Patients with IBS may have organic lesions detectable at colonoscopy.

Methods: A cross sectional study was carried out in 140 consecutive patients of IBS fulfilling the ROME IV criteria. The study was conducted in Gastroenterology unit, Department of Medicine, Bir hospital, Kathmandu from July 2016 to September 2017. All patients underwent full colonoscopy along with biopsy from sigmoid colon and any visibly abnormal areas.

Results: The average age of patients was 37.5 years with $76(52.8 \%)$ males. Forty-two (30\%) had IBS-D, $36(26 \%)$ had IBS-C, 31 (22\%) had IBS-M and $31(22 \%)$ had IBS-U. Dyspepsia was seen in $16(11.4 \%)$ and fear of TB/Malignancy/IBD was seen in $27(19.2 \%)$. Organic lesions were seen in $39(27.85 \%)$ patients. Nonspecific colitis was seen in $10(7.1 \%)$ followed by ileal erosions in $7(5 \%)$, polyps in $8(5.7 \%)$, hemorrhoids in $6(4.2 \%)$ and diverticula in $3(2.1 \%)$. Only one $(0.71 \%)$ patient had microscopic colitis and one $(0.71 \%)$ had malignant lesion seen at histopathological examination. Females with IBS-D had more organic findings than males $(P=0.03, R R=4.13,95 \% C I=1.21-15.71)$.

Conclusions: The prevalence of organic lesions in patients with IBS fulfilling ROME IV criteria is $27 \%$. Dyspepsia is the most common comorbidity and fear of TB/malignancy/IBD is the most common reason for seeking health care. Females with IBS-D have a higher risk of detecting organic lesions by colonoscopy and histopathology examination.

Keywords: colonic lesions; colonoscopy; histopathology; irritable bowel syndrome; ROME IV criteria.

\section{INTRODUCTION}

Irritable bowel syndrome (IBS) occurs as recurrent abdominal pain that is related to defecation and associated with a change in frequency and/or form of stool. It is one of the disorders of brain-gut interaction (DBGI). ${ }^{1}$ Fulfillment of Rome criteria and lack of warning signs is necessary to make a positive diagnosis of IBS. ${ }^{2}$

Prevalence of celiac disease is increased in patients with
IBS. ${ }^{3}$ There is also an overlap in patients with IBS and microscopic colitis/inflammatory bowel disease (IBD).$^{4,5}$ IBS patients have a high incidence of gastrointestinal

Correspondence: Dr. Mukesh Sharma Paudel, Gastroenterology Unit, Department of Medicine, Bir Hospital, Kathmandu, Nepal. Email: drmuku@gmail.com, Phone: +977-9844700043. 
comorbidities. ${ }^{6}$ Few studies in past have looked into the prevalence of organic lesions in patients with IBS. ${ }^{7-11}$

This study aimed to estimate the prevalence of organic lesions by colonoscopy in patients with IBS using the ROME IV criteria. We also aimed to study the comorbidities and reasons for seeking health care in patients with IBS.

\section{METHODS}

A cross sectional study was carried out in patients attending the out patients department of Gastroenterology unit at National Academy of Medical Sciences (NAMS), Bir hospital, Kathmandu. Recruitment was started from July 2016 onwards after taking approval from institutional review board of NAMS. Sample size was calculated as follows:

$\mathrm{ME}=\mathrm{z} \sqrt{\mathrm{p}(1-\mathrm{p})} / \mathrm{n}$

Where ME is desired margin of error, $z$ is the $z$ score, $p$ is the estimated prevalence of the disease and $n$ is the sample size. After substituting $\mathrm{z}=1.96, \mathrm{ME}=5, \mathrm{P}=$ $10 \%$, we determined the sample size for the study to be $138 .{ }^{12}$ We planned to recruit consecutive patients of IBS who presented to the gastroenterology OPD. We included patients who met the ROME IV criteria for IBSviz recurrent abdominal pain on average at least one day a week in the last three months and symptoms starting at least six months prior associated with two or more of the following: related to defecation, associated with a change in a frequency of stool or associated with a change in form (consistency) of stool. ${ }^{13} \mathrm{We}$ excluded patients with prior abdominal surgeries, previously identified comorbidities that could explain their gastrointestinal (GI) symptoms, patients who had undergone colonoscopy is past six months, patients with alarm features (onset at greater than 50 years of age, weight loss, blood in the stool, or a family history of inflammatory bowel disease), pregnant women and patients with disorders of thyroid gland.

Patients were asked to recall their stool pattern of abnormal defecation for two weeks on the basis of Bristol stool scale. ${ }^{14}$ This scale classifies stool pattern on the basis of its appearance and the scale ranges from 1 to 7. IBS with predominant constipation (IBS-C) had $>25 \%$ of bowel movements with Bristol stool form type 1 or 2 and $<25 \%$ bowel movements with Bristol stool form types 6 or 7. IBS with predominant diarrhea (IBS-D) had $>25 \%$ of bowel movements with Bristol stool form type 6 or 7 and $<25 \%$ of bowel movements with Bristol stool form type 1 or 2. IBS with mixed bowel habits (IBS-M) had $>25 \%$ of bowel movements with Bristol stool form types 1 or 2 and $>25 \%$ of bowel movements with Bristol stool form type 6 or 7 .
IBS unclassified (IBS-U) met the diagnostic criteria for IBS but their bowel habits could not be categorized into any of above subtypes. ${ }^{13}$

All eligible patients underwent full colonoscopy after bowel preparation and informed consent. Bowel preparation was done with two tablets of $10 \mathrm{mg}$ Bisacodyl in the preceding evening followed by two liters of polyethylene glycol preparation on the morning of the day of colonoscopy. All colonoscopies were performed by FUJINON colonoscope and by endoscopist swith more than five years of experience in performing colonoscopies. Multiple (two to five) mucosal biopsies were taken from sigmoid colon and any visibly abnormal areas of the colon or terminal ileum. Data was also collected regarding alcohol consumption, smoking and tobacco chewing habits. Duration of symptoms of IBS and comorbid conditions were noted. Patients were asked about their reasons for seeking health care.

Data were entered into Microsoft EXCEL and analyzed using SPSS version 22 software. Continuous data were expressed as mean and standard deviation, and categorical data as number (\%). In case of continuous variables, unpaired t-test was used to compare the difference between means. Chi-square/Fischer's exact test was used to compare the categorical variables. When comparing the comorbidities between the groups with or without organic lesions, two categories of $<$ two co-morbidities and $\geq$ two co-morbidities were compared. This cut-off was taken because it has been shown that excess comorbidity is present in only subset of patients with IBS. ${ }^{15}$

\section{RESULTS}

A total of 140 patients were enrolled and analyzed. Forty-two (30\%) had IBS-D, $36(25.7 \%)$ had IBS-C, $31(22.1 \%)$ had IBS-M and $31(22.1 \%)$ had IBS-U. The age range of participants was 15-62 years with a mean age of $37.5 \pm 10.18$ years. Our study had a predominance of male gender $76(52.8 \%)$. The average duration of symptoms in all IBS patients was 15 months and a range of six to 180 months. We did not observe any significant difference among the subtypes of IBS in terms of age $(p=0.35)$, gender $(P=0.42)$, the pattern of alcohol use/ smoking/ tobacco chewing ( $P=0.69)$, duration of symptoms of IBS ( $P=0.42)$ and the presence or absence of organic lesions $(P=0.89)$.

The reason for seeking health care could be elicited in $74(52.8 \%)$ patients. Sixty-six $(47.1 \%)$ patients did not give a precise reason for seeking health care. Fear of developing TB/Malignancy/inflammatory bowel disease 
appears to be the most common cause for seeking health care among the study participants which was seen in $27(19.2 \%)$ (Figure 1).

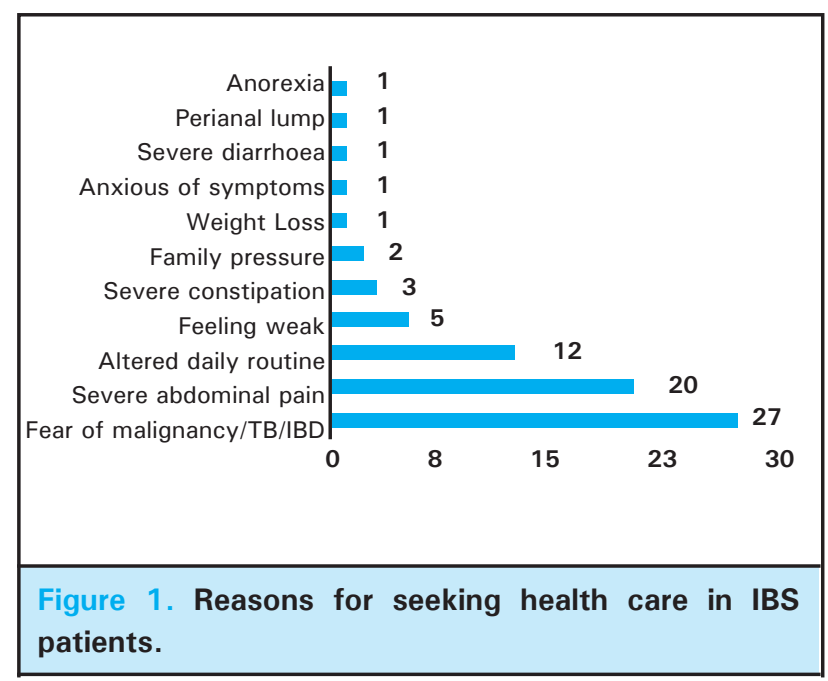

Comorbid conditions were seen in $81(57.8 \%)$ patients. Two or more comorbidities occurred simultaneously in $11(7.85 \%)$ patients (Figure 2).

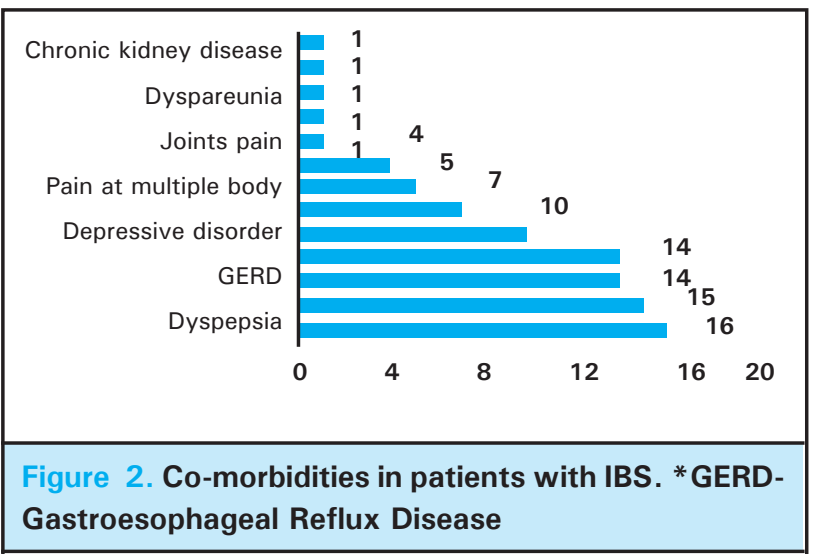

Findings at colonoscopic examination were seen in 38 $(27.1 \%)$ patients. In our study, rectal erosions and ulcers were the most common findings at colonoscopy which were seen in $10(7.14 \%)$ patients (Figure 3).

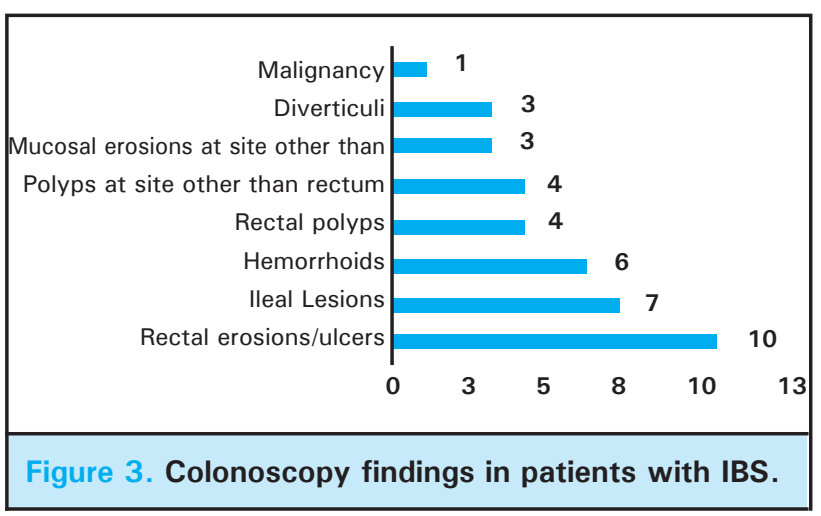

Diverticula was found to be right sided in two and bilateral in one patients. Eleven patients (26.1\%) with IBS-D had positive findings on colonoscopic examination; among patients with IBS-C, 11 (30.5\%) had lesions on colonoscopic examination; among patients with IBS-M, 9 (29.0\%) had positive findings on colonoscopic examination and among patients with IBS-U, 7 (22.5\%) had positive findings on colonoscopy. Chi square $\left(\chi^{2}\right)$ test for independence was used to compare the difference between the positive colonoscopy finding and no colonoscopy finding among the four IBS subtypes. The difference was not statistically significant $(P=0.61)$.

Positive findings at histopathological examination were seen in $30(21.4 \%)$ patients. Nonspecific colitis was the most common finding seen in $10(7.14 \%)$ (Figure 4).

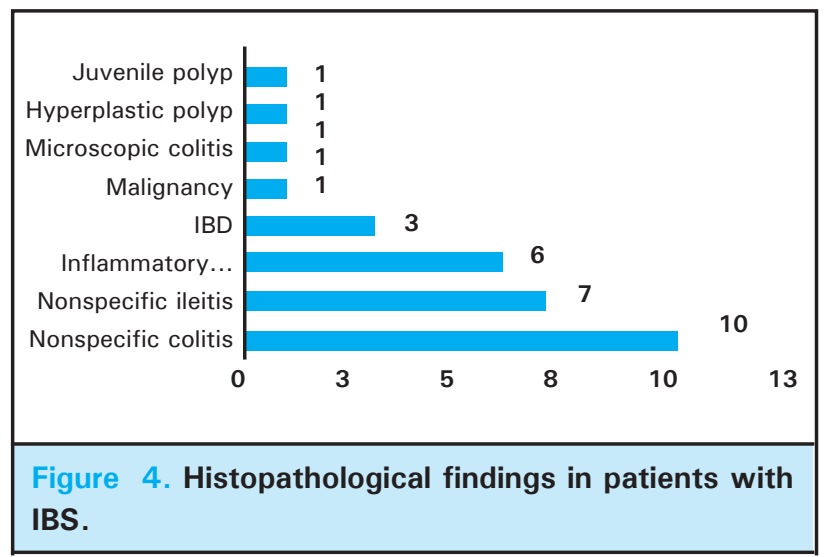

Abnormal findings on histological examination were present in 12 (28.5\%) patients with IBS-D, five (13.8\%) patients with IBS-C, nine $(29.0 \%)$ patients with IBS-M and four $(12.9 \%)$ patients with IBS-U. Chi square $\left(x^{2}\right)$ test for independence was used to compare the difference between occurrences of histological lesions among IBS subtypes. The difference was not found to be statistically significant $(P=0.18)$.

Thus, in our study, number of patients with positive findings in either colonoscopy or HPE were 39 $(27.85 \%)$. Among patients with IBS-D, organic lesions were present in 12 (28.5\%); among patients with IBS-C, organic lesions were present in 11 (30.5\%); among patients with IBS-M, organic lesions were present in nine $(29.0 \%)$ and among patients with IBS-U, organic lesions were present in seven $(22.5 \%)$. Chi-squared test for independence was used to compare the difference in presence or absence of organic lesions among IBS subtypes. The difference was not statistically significant $(P=0.89)$.

We compared the two groups of patients with or without organic findings across the IBS subtypes. The difference in age distribution in the two groups was not significant in any of IBS subtypes: IBS-D $(P=0.94)$, 
IBS-C $(P=0.35)$, IBS-M (0.91) and IBS-U $(P=0.60)$. No difference was seen between the two groups in patients with IBS-C $(P=0.46)$, IBS-M $(P=0.25)$ and IBS-U $(P=0.68)$ with regards to gender distribution. In patients with IBS-D, a difference in gender distribution was seen between the two groups (Table 1).

\begin{tabular}{|llll|}
\hline $\begin{array}{l}\text { Table 1. Gender distribution in patients with IBS-D } \\
\text { based on organic lesions. }\end{array}$ \\
\hline $\begin{array}{l}\text { IBS-D } \\
(\mathrm{n}=42)\end{array}$ & $\begin{array}{l}\text { Organic } \\
\text { findings } \\
\mathrm{n}(\%)\end{array}$ & $\begin{array}{l}\text { No organic } \\
\text { findings } \\
\mathrm{n}(\%)\end{array}$ & $\mathrm{P}$ value \\
Females & $10(24 \%)$ & $13(40 \%)$ & 0.03 ( Fischer's \\
Males & $2(5 \%)$ & $13(31 \%)$ & $\begin{array}{l}\text { exact test); } \\
\mathrm{RR}=4.13,95 \% \\
\mathrm{Cl}=1.21-15.71)\end{array}$ \\
\hline
\end{tabular}

No difference was seen between the two groups over all IBS subtypes in terms of duration of symptoms, reasons for seeking health care and presence of comorbidities.

\section{DISCUSSION}

The aim of this study was to identify the prevalence of organic lesions in patients with IBS fulfilling the ROME IV criteria. Colonoscopy and histopathological examination detected the organic lesions in $39(27.8 \%)$ patients. Comorbidities were seen in $81(57.8 \%)$ patients.

The most common subtype of IBS seen in our study was IBS-D. This is similar to another multicenter study from China where 735 patients met the ROME III criteria of IBS and the most common subtype of IBS seen was IBS-D. ${ }^{16}$ The average age of patients with IBS in our study was 37.5 years which is only slightly higher to the average age of 32.3 years seen from a survey in Bangladesh. ${ }^{17}$ Most patients with IBS were in the age range of 30-39 years. This finding in our study is also supported by a survey from South Korea. ${ }^{9}$

Although it is said that IBS favors female sex in the west, there is inconsistency in the gender distribution of IBS reported from Asia. ${ }^{18,19}$ In our study, we observed a predominance of male gender among the patients who presented to hospital with IBS symptoms. In a hospital based study such as ours, males are more likely to seek health care in a male-dominant society. In a study from Pakistan on health care workers with symptoms of IBS, males outnumbered females [28 $(68.2 \%)$ vs 13 $(31.7 \%)$. $^{20}$

Psychiatric diagnosis in patients with IBS has a powerful influence on health care seeking. ${ }^{21}$ Depression or anxiety disorder was seen in $24(17.1 \%)$ patients in our study and 27 (19.2\%) had fear of developing TB, malignancy or IBD. This may reflect poor understanding of IBS symptoms in our patients. Seventy three percent of patients in one study had sought medical care for abdominal pain or discomfort. ${ }^{22}$ Severe abdominal pain was the second most common cause of seeking health care in our study. A significantly elevated prevalence of gastrointestinal co-morbidities like GERD and dyspepsia were also seen in our study; which can be seen in IBS patients. ${ }^{15}$ Excess co-morbidities are however present in only a subset of patients. ${ }^{15}$ In our study, $11(7.85 \%)$ had simultaneous occurrence of two or more comorbidities.

Various studies have described a prevalence rate of organic lesions in patients with IBS to be around 10\% to $40 \% \cdot{ }^{10-12,23}$ None of these studies had used ROME IV criteria for the diagnosis of IBS. In a study by Patel et al in 2015, $138(24.7 \%)$ of 559 patients meeting criteria for IBS were found to have organic disease after investigation. ${ }^{8}$ This is similar to $27 \%$ patients seen with positive findings in colonoscopy in our study. In a retrospective study from China, organic colonic lesions were found in $30.3 \%$ of the patients with suspected IBS $(1,010 / 3,332) .{ }^{10}$ The most common organic finding in our study was visible rectal erosions and ulcers on colonoscopy in $10(7.14 \%)$ and non-specific colitis on histopathological examination in 10 (7.14\%). Nonspecific colitis was also seen in $5.7 \%$ patients in one retrospective study. ${ }^{10}$ Pironti et al found non-specific colitis in $25 \%$ of colonic biopsies from 92 patients with IBS. ${ }^{24}$ Crohn's disease was the most common organic finding in the study by Patel et al. ${ }^{8}$ In the Korean study, polyps were seen in $71(40 \%)$ as compared to $8(5.6 \%)$ in our study. ${ }^{9}$

Left sided diverticular disease (odds ratio, $3.1 ; 95 \% \mathrm{Cl}$ : 1.4-7.1; $\mathrm{P}=0.006$ ) and bilateral diverticular disease (odds ratio, $2.6 ; 95 \% \mathrm{Cl}: 1.3-5.2 ; \mathrm{P}=0.007$ ) are also shown to be independent risk factors for IBS. ${ }^{25}$ In our study two (out of three) patients had left sided diverticula and one had bilateral diverticular disease. In our study only one $(0.71 \%)$ patient fulfilling the ROME IV criteria for IBS had microscopic colitis. This is different than the prevalence of $3.09 \%(7 / 226)$ in IBS patients observed in another study. ${ }^{26}$

The only difference we found in our study among patients who did or did not have organic lesions was the gender distribution in patients with IBS-D. Females with IBS-D had a higher chance of organic findings during colonoscopy examination with biopsy of visibly normal areas. This may be because of difference in health care seeking behaviors between males and females. A cohort study from Netherlands has shown that patients who fulfill ROME IV criteria for IBS are most likely to be young females with higher overall GI symptom severity, including comorbid psychological 
Paudel et al. Prevalence of Organic Colonic Lesions by Colonoscopy in Patients Fulfilling ROME IV Criteria of Irritable Bowel Syndrome

symptoms and lower quality of life compared with the Rome III IBS population. ${ }^{27}$ However, it has also been noted that women with IBS were more likely to exhibit the constipation-predominant subtype (OR: 2.38; $95 \% \mathrm{Cl}: 1.45-3.92)$, and less likely to meet criteria for the diarrhea-predominant subtype (OR: $0.45 ; 95 \% \mathrm{Cl}$ : $0.32-0.65)$ than men with IBS. ${ }^{28}$

Our study has a few limitations. We could not recruit consecutive patients of IBS presenting to our OPD as initially planned. The subtype classification of IBS was based on participant's recall of stool form.

\section{CONCLUSIONS}

The prevalence of organic findings in patients with IBS fulfilling ROME IV criteria is $27 \%$. Females with IBS-D have a higher risk of detecting organic findings by colonoscopy and/or histopathological examination. Dyspepsia is the most common co-morbidity and fear of developing TB, malignancy or IBD is the most common reason for seeking health care in patients with IBS. We recommend eliciting the presence of comorbidities and reason for seeking health care in patients with IBS.

\section{Conflict of Interest: None.}

\section{REFERENCES}

1. Schmulson MJ, Drossman DA. What is new in Rome IV.J Neurogastroenterol Motil. 2017 Apr 30;23(2):151-63. [PubMed | DOI | Full Text]

2. Vanner S, Depew W, Paterson W, DaCosta L, Groll A, Simon $\mathrm{J}$, et al. Predictive value of the Rome criteria for diagnosing the irritable bowel syndrome. Am J Gastroenterol. 1999 Oct;94(10):2912-7. [PubMed | DOI | Full Text]

3. Ford AC, Chey WD, Talley NJ, Malhotra A, Spiegel BM, Moayyedi P. Yield of diagnostic tests for celiac disease in individuals with symptoms suggestive of irritable bowel syndrome: systematic review and meta-analysis. Arch Intern Med. 2009 Apr 13;169(7):651-8. [PubMed | DOI | Full Text]

4. Pardi DS, Limsui D. Utility of symptom-based criteria for evaluating patients with chronic diarrhea. Gastrointest Endosc. 2005 Oct;62(4):649. [PubMed | DOI | Full Text]

5. Chey WD, Kurlander J, Eswaran S. Irritable bowel syndrome: a clinical review. JAMA. 2015 Mar 3;313(9):949-58. [PubMed | DOI $\mid \underline{\text { Full Text] }}$

6. Riedl A, Schmidtmann M, Stengel A, Goebel M, Wisser A-S, Klapp BF, et al. Somatic comorbidities of irritable bowel syndrome: a systematic analysis. J Psychosom Res. 2008 Jun;64(6):573-82. [․ㅏbMed | DOI | Full Text]

7. Akhtar AJ, Shaheen MA, Zha J. Organic colonic lesions in patients with irritable bowel syndrome (IBS). Med Sci Monit. 2006 Sep;12(9):CR363-7. [uㅏMed | Full Text]

8. Patel P, Bercik P, Morgan DG, Bolino C, Pintos-Sanchez MI, Moayyedi $\mathrm{P}$, et al. Prevalence of organic disease at colonoscopy in patients with symptoms compatible with irritable bowel syndrome: cross-sectional survey. Scand J Gastroenterol. 2015 Jul;50(7):816-23. [ubMed | DOI | Full Text]

9. Park KS, Ahn SH, Hwang JS, Cho KB, Chung WJ, Jang BK, et al. A survey about irritable bowel syndrome in South Korea: prevalence and observable organic abnormalities in IBS patients. Dig Dis Sci. 2008 Mar;53(3):704-11. [PubMed | Full Text]
10. Gu H-X, Zhang Y-L, Zhi F-C, Jiang B, Huang Y. Organic colonic lesions in 3,332 patients with suspected irritable bowel syndrome and lacking warning signs, a retrospective case-control study. Int J Colorectal Dis. 2011 Jul;26(7):935-40. [PubMed | Full Text]

11. Chey WD, Nojkov B, Rubenstein JH, Dobhan RR, Greenson JK, Cash BD. The yield of colonoscopy in patients with non-constipated irritable bowel syndrome: results from a prospective, controlled US trial. Am J Gastroenterol. 2010 Apr;105(4):859-65. [ㅁubMed | Full Text]

12. Ishihara S, Yashima K, Kushiyama Y, Izumi A, Kawashima $\mathrm{K}$, Fujishiro $\mathrm{H}$, et al. Prevalence of organic colonic lesions in patients meeting Rome III criteria for diagnosis of IBS: a prospective multi-center study utilizing colonoscopy. J Gastroenterol. 2012 Oct;47(10):1084-90. [PubMed | Full Text]

13. Lacy BE, Mearin F, Chang L, Chey WD, Lembo AJ, Simren M, et al. Bowel disorders. Gastroenterology. 2016;150(6):1393-407.e5. [Full Text | DOI | PubMed]

14. Lewis S, Heaton K. Stool form scale as a useful guide to intestinal transit time. Scand J Gastroenterol. 1997 Sep;32(9):920-4. [PubMed |Full Text]

15. Whitehead WE, Palsson OS, Levy RR, Feld AD, Turner M, Von Korff M. Comorbidity in irritable bowel syndrome. Am J Gastroenterol. 2007 Dec;102(12):2767-76. [마bMed | Full Text].

16. Yao X, Yang YS, Cui LH, Zhao KB, Zhang ZH, Peng LH, et al. Subtypes of irritable bowel syndrome on Rome III criteria: a multicenter study. J Gastroenterol Hepatol. 2012 Apr;27(4):760-5. [ubMed | Full Text]

17. Masud MA, Hasan M, Khan AK. Irritable bowel syndrome in a rural community in Bangladesh: prevalence, symptoms pattern, and health care seeking behavior. Am J Gastroenterol. 2001 May;96(5):1547-52. [PubMed | Full Text] 
18. Sperber AD, Dumitrascu D, Fukudo S, Gerson C, Ghoshal UC, Gwee KA, et al. The global prevalence of IBS in adults remains elusive due to the heterogeneity of studies: a Rome Foundation working team literature review. Gut. 2017. Jun;66(6):1075-82. [uuMed | Full Text]

19. Chang FY, Lu CL, Chen TS. The current prevalence of irritable bowel syndrome in Asia. J Neurogastroenterol Motil. 2010 Oct;16(4):389-400. [Full Text | PubMed]

20. Jafei W, Yakoob J, Jafri N, Maloni M, Hamid S, Shah HA, et al. Irritable bowel syndrome in health care professionals in Pakistan. JPMA The Journal of the Pakistan Medical Association. 2003;53(9):405-7. [ㄷll Text | PubMed]

21. Hoeper EW, Nycz GR, Regier DA, Goldberg ID, Jacobson A, Hankin J. Diagnosis of mental disorder in adults and increased use of health services in four outpatient settings. Am Psychiatry. 1980 Feb;137(2):207-10. [Full Text | DOI | PubMed]

22. Talley NJ, Boyce PM, Jones M. Predictors of health care seeking for irritable bowel syndrome: a population based study. Gut. 1997 Sep;41(3):394-8. [PubMed]

23. Akhtar AJ, Shaheen MA, Zha J. Organic colonic lesions in patients with irritable bowel syndrome (IBS). Med Sci Monit. 2006 Sep;12(9):CR363-7. [ Full Text | PubMed ]
24. Pironti A, Tadeu V, Pedroni A, Porcu A, Manca A, Massarelli $\mathrm{G}$, et al. Role of routine small intestinal biopsy in adult patient with irritable bowel syndrome-like symptoms. Minerva Med. 2010 Jun;101(3):129-34. [ Full Text | PubMed ]

25. Yamada E, Inamori $M$, Uchida $E$, Tanida E, Izumi $M$, Takeshita K, et al. Association between the location of diverticular disease and the irritable bowel syndrome: a multicenter study in Japan. Am J Gastroenterol. 2014 Dec;109(12):1900-5. [ Full Text | DOI | PubMed ]

26. Ozdil K, Sahin A, Calhan T, Kahraman R, Nigdelioglu A, Akyuz $\mathrm{U}$, et al. The frequency of microscopic and focal active colitis in patients with irritable bowel syndrome. BMC Gastroenterol. 2011;11:96. [ Full Text | DOI | PubMed ]

27. Vork L, Weerts ZZ, Mujagic Z, Kruimel JW, Hesselink MA, Muris JW, Keszthelyi D, Jonkers DM, Masclee AA. Rome III vs Rome IV criteria for irritable bowel syndrome: A comparison of clinical characteristics in a large cohort study. Neurogastroenterol Motil. 2017 Aug 14. [ Full Text | DOI | PubMed ]

28. Lovell RM, Ford AC. Effect of gender on prevalence of irritable bowel syndrome in the community: systematic review and meta-analysis. Am J Gastroenterol. 2012 Jul;107(7):991-1000. [ DOI | PubMed ] 